\title{
Editorial
}

\section{Food Safety in Bangladesh}

\section{MY Ali}

Any substance consumed to provide nutritional support for the body is food. The right to food is a human right recognizing the "right to an adequate standard of living including adequate food,"as well as the "fundamental right to be free from hunger."

We eat food to live. Besides, we take fruits to our relative's house who is sick. We buy large fish from our favorite superstore to entertain our guest. We celebrate the good result of our kid with sweets. All these activities are actually very common in our society and they bring smile to our loved ones and also give us immense pleasure. However, the irony is that these can also be the source of sickness for our dear one. So, we are concerned about safe food. Unsafe food can be a significant reason of many acute and chronic diseases.

In Bangladesh, most of the foods which are manufactured or processed are unsafe for consumption and also adulterated to varying degrees. This problem persists at every level of the food chain from preparation to consumption. Food manufacturers, processors, restaurants, fast food outlets and so forth are all involved in one way or another in this corrupt practice of adulteration by using various harmful chemicals and toxic artificial colours. On the other hand, perishable foods are turned to poisonous foods as these are stored, sold and served to consumers in an unhygienic atmosphere.

The range of chemicals and colouring agents that are being used in food is beyond imagination. Calcium carbide is applied on fruits to ripen, formalin on fish, fruits, milk and vegetables as preservatives, brick dust and poisonous yellow colorants in spices, urea to whiten rice and puffed rice, sawdust in loose tea, soap in ghee and artificial sweetener, coal tar and textile dyes in sweetmeats. Various colouring agents are used in sauces, juices, lentils and oils. Sulphuric acid is used in milk for condensation. Many restaurants use burnt engine oil for deep fry. Even the cooking oil becomes poisonous due to repetitive use of same oil in restaurants. We feel utterly helpless when we come to know that between $70 \%-90 \%$ of the food products available in markets are contaminated by underlying one way or another.

\section{Unhygienic practice in food handling}

Unhygienic food is a significant reason of diarrhoeal diseases as well as malnutrition ${ }^{1}$. In addition unhygienic processing of food has a severe impact on the export facilities in Bangladesh. For example, in 1997 European Union banned importing shrimp from Bangladesh due to the lack of maintaining proper hygiene standards in the shrimp processing plants ${ }^{2}$.

\section{Use of formalin, carbide and DDT in foods}

Supermarkets openly sell fruits, fishes and vegetables that have been treated with formalin to keep them fresh. Consumption of formalin directly through food can cause different types of cancers especially the lung cancer $^{3}$. Use of calcium carbide for ripening foods specially mangoes produce various health problems like headache, dizziness, mood disturbance, sleepiness, Address of correspondence :

Dr. Md. Yusuf Ali, MBBS, FCPS (Medicine), Professor and Head, Department of Medicine, Faridpur Medical College.

Email: mdyusufali1958@gmail.com, Phone No: +8801711425121 mental confusion, memory loss and seizure. DDT is commonly used in dried fish processing. Using of DDT is a significant reason of cancer especially in breast, liver, pancreas and some reproductive problems ${ }^{4}$.

\section{Use of toxic colours in food}

Generally, these harmful colours are used to make foods attractive, appealing and appetizing. These are applied in the various types of sweets, some cultural foods named beguni, peaju. etc. These can create indigestions, vomiting, diarrhoea, allergy, asthma, several kinds of neurological diseases and even cancer ${ }^{6}$.

\section{Other food adulterations}

The puffed rice is contaminated by using urea fertilizer and cadmium. Urea is extremely hazardous for human body which can create cancer and various ulcers. Exposure to cadmium is linked with kidney disease.

The urge of making profit at any cost and moral degradation among food traders are the fundamental reason of all the malpractice. Manufacturers, farmers, processors, transporters, middlemen, sellers-everyone to some extend, is involved in this process. Lack of awareness, negligence and indifference among consumers are also obstacles to ensuring food safety. We are not aware about our consumer rights.

Access to safe and nutritious food along with food security is of utmost importance to reach the Millennium Development Goal of reducing hunger and under nourishment in Bangladesh by 2015 . The theme of this year's World Health Day is 'Food Safety' which is very much relevant \& close to Bangladeshi context. Everyone's collective effort can reduce food adulteration which is a punishable offence and government should take serious action against it. The government along with non-governmental and private sectors should frame out national plan to create public awareness about food safety and health hazards. However, the good news is that the government of Bangladesh started implementing the Safe Food Act 2013 from February 2015 to fight adulteration and protect public health. Everyone should work towards the common motto: safe food from farm to plate. Only then it will be possible to ensure food safety.

\section{References :}

1. Motarjemi Y, Kaferstein F, Moy G, Quevedo F. Contaminated Weaning Food: A Major Risk Factor for Diarrhoea and Associated Malnutrition. Bull World Health Organ. 1993;71(1):79-92.

2. Alam SMN, Pokrant B. Re-organizing the Shrimp Supply Chain: Aftermath of the 1997 European Union Import Ban on the Bangladesh Shrimp. Aquaculture Economics \& Management 2009; $13: 53$.

3. Greg AW, Casandra MM, Paul RB. Human Health Risks Associated with Formalin Treatments Used in Aquaculture: Initial Study. North American Journal of Aquaculture 2005; 67:111.

4. Chowdhury MAZ, Amin-ud-Din M, Malek MA, Zaman MA. DDT residue and its metabolites in dried fishes of Dhaka city markets. Soil \& Environ. 29(2):117-121.

5. Pratimo Rao, Ramesh VB. A Comparative Study on the Synthetic Food Colours Usage in Foods Procured from Urban and Rural Areas of Hyderabad. Nutrition and Food Science 2003; 33:230.

6. Jack LR. Toxicology of Food Colors. Annual Review of Pharmacology 1974; 14:127-37. 